Anthony C. Webster BSc MB ChB FFARCS FRCPC, James D. McKishnie MD FRCPC, Cynthia F. Kenyon MD FRCPC, Donald G. Marshall MD FAAP FRCSC

\title{
Spinal anaesthesia for inguinal hernia repair in high-risk neonates
}

To avoid the high incidence of respiratory complications associated with general anaesthesia in premature neonates, 44 spinal anaesthetics for inguinal hernia repair in very low birthweight infants were administered in 47 attempts. Hyperbaric tetracaine with epinephrine 1:200,000 was administered in a dose range of $0.27-1.10 \mathrm{mg} \cdot \mathrm{kg}^{-1}$. Attempted lumbar puncture failed in three infants. In 24 procedures, spinal anaesthesia alone provided satisfactory operating conditions; in 20. supplementary inhalational general anaesthesia or iv ketamine was necessary. Perioperative apnoeic episodes requiring bag/mask assisted ventilation occurred in six infants. In five infants, apnoeic spells occurred in the postoperative period. No infant required tracheal intubation; there was no haemodynamic instability. Twenty-four infants required no postoperative analgesia. Our experience suggests that spinal anaesthesia for inguinal hernia repair in very low birth weight infants reduces but does not eliminate the risk of respiratory instability, and that supplementary anaesthesia is often necessary to provide satisfactory operating conditions.

Dans le but d'échapper aux complications respiratoires de l'anesthésie générale, nous avons réussi 44 rachidiennes en 47 essais pour fin d' herniotomie inguinale chez de grands prématurés en employant de $0,27 \dot{a} 1,10 \mathrm{mg} \cdot \mathrm{kg}^{-1}$ de tétracaine hyperbare avec adrénaline 1:200000. Nos tentatives de ponction lombaire ont échoué trois fois. Chez 24 enfants, l'anesthésie rachidienne s'avéra suffisante mais chez 20 autres, on dut lui ajouter des anesthésiques en inhalation ou de la kétamine iv. Des épisodes d'apnée survinrent en période

\section{Key words}

ANAESTHETIC TECHNIQUES: spinal; ANAESTHESIA: paediatric, neonatal; VENTILATION: apnoea; SURGERY: paediatric.

From the Departments of Anacsthesia, Nconatal-Perinatal Medicine and Surgery, St. Joseph's Health Centre, University of Western Ontario, London, Canada.

Address correspondence to: Dr. A. C. Webster, Deparment of Anacsthesia, St. Joseph's Health Centre, 268 Grosvenor Street, London, Ontario, Canada, N6A 4V2.

Accepted for publication 27 th November, 1990. péri-opératoire chez six des enfants ayant reşu des anesthésiques en inhalation. En tout, cinq enfants eurent des épisodes d'apnée en période postopératoire mais aucun n'eut besoin d'une intubation trachéale. Les variables hémodynamiques furent toujours stables. Vingt-quatre enfants n'eurent besoin d'aucun analgésique en période postopératoire. Bref, l'anesthésie rachidienne pour herniotomie inguinale chez les prémaıurés de très petit poids n'élimine pas tous les risques de complication respiratoire et ne suffit souvent pas à produire une anesthésie chirurgicale.

Due to advances in perinatology and neonatal intensive care, more neonates survive the immediate perils of extreme prematurity. Prolonged ventilator care in this patient population is accompanied by the risk of bronchopulmonary dysplasia (BPD) and subglottic stenosis. ${ }^{1}$ Respiratory control mechanisms are often unstable ${ }^{2}$ and the risk of apnoeic episodes is aggravated by general anaesthesia. ${ }^{3-6}$ There is a high incidence of inguinal hernias, up to $30 \%$ in infants less than $1000 \mathrm{~g}$ birth weight. ${ }^{7}$ Early surgical correction is required to reduce the risk of incarceration. Following the report of Abajian et al. in $1984,{ }^{8} 44$ spinal anaesthetics were administcred for inguinal hernia repair to 34 very low birthweight infants from our Neonatal Intensive Care Unit.

\section{Methods}

\section{Preoperative care}

After the hernia was diagnosed, efforts were directed towards delaying surgery until the infant reached $2200 \mathrm{~g}$ and was otherwise fit for discharge from hospital. To reduce the risk of incarceration and to alleviate parental anxiety, the repair was completed before the infant left the neonatal intensive care nursery. Large hernias were reduced every two hours. In 22 of the 37 infants, inguinal hernia repair was performed during the course of treatment in the intensive care nursery; in 15, the hernia appeared after the infant had been discharged to home care. In the latter group, the infant was admitted to the paediatric ward on the day before surgery, and discharged on the following day. The characteristics of the patient population are shown in Tables I and II. 
TABLE I Demographic data

\begin{tabular}{lc}
\hline Number of patients (male 31. female 6) & 37 \\
Mean gestational age (wk) & $28.16 \pm 3.85$ \\
Mean birth weight (g) & $922.97 \pm 279.45$ \\
Appropriate for gestational age (AGA) & $25(68 \%)$ \\
Small for gestational age (SGA) & $12(32 \%)$ \\
<1000 g birth weight & $23(62 \%)$ \\
Number ventilated following birth & $31(84 \%)$ \\
Mean days ventilated & $44.87 \pm 37.12$ \\
Mean days oxygen therapy & $87.03 \pm 79.79$ \\
Bronchopulmonary dysplasia (BPD) & $27(73 \%)$ \\
\hline
\end{tabular}

Spinal anaesthesia was performed with parental consent and review of the records was approved by the Medical Records and Research Committees of St. Joseph's Health Centre. Contraindications included coagulopathies, systemic infections, meningitis, hypovolaemia, infection at the puncture site, and intracranial bleeding, hypertension or cerebrospinal fluid (CSF) draining catheter.

Normal oral intake was allowed up to four hours before surgery for infants not maintained on $i v$ feeding. A secure iv infusion was started before anaesthesia and 5\% dextrose in $0.225 \%$ saline was administered at a rate of $5.0 \mathrm{ml} \cdot \mathrm{kg}^{-1} \cdot \mathrm{hr}^{-1}$ by means of an infusion pump. The infant was brought to the previously warmed operating room $\left(25^{\circ} \mathrm{C}\right)$ in a warmed transport isolette with ECG monitoring and oxygen administration as necessary. The nurse accompanying the infant from the intensive care nursery assisted with monitoring, positioning the infant

TABLE II NICU and ward data

NICU patients $n=22$

- Oxygen therapy

- Respiratory stimulants

- Postconceptional age (wk)

- Weight (g)

$$
\begin{aligned}
& 10(27 \%) \\
& 2(5 \%) \\
& 40.54 \pm 2.18 \\
& 2335.56 \pm 320.21 \\
& \text { (range } 1690-3200)
\end{aligned}
$$

Paediatric ward patients $n=15$

- Postconceptional age (wk)

- Weight (g)

$48.02 \pm 12.02$

$3710.87 \pm 1138.83$ for lumbar puncture and administration of intravenous fluids.

\section{Anaesthetic and surgical technique}

Preparations were made for general anaesthesia and resuscitation and additional monitoring transducers were applied: pulse oximeter, automatic electronic oscillometer blood pressure cuff, precordial stethoscope. Atropine $0.02 \mathrm{mg} \cdot \mathrm{kg}^{-1}$ was administered $i v$ before lumbar puncture. A rectal temperature probe was placed during positioning before surgery.

In the first seven cases, lumbar puncture was attempted with the infant in the lateral decubitus position with partial neck extension. The mean dose of tetracaine, based on Abajian's report and a study by Dohi, ${ }^{9}$ was $0.29 \mathrm{mg}$. $\mathrm{kg}^{-1}$. There were two failures, and in two others lumbar puncture was difficult and the duration of spinal anaesthesia did not allow completion of surgery without supplementary inhalational anaesthesia. In all subsequent cases, spinal anaesthesia was induced with the infant sitting with the head supported and somewhat extended. Lumbar puncture was performed in the mid-line in the $\mathrm{L}_{4-5}$ interspace with a $22 \mathrm{G} 4 \mathrm{~cm}$ or a $25 \mathrm{G} 2.5 \mathrm{~cm}$ spinal needle. The calculated dose of tetracaine $1 \%$, with an equal volume of $10 \%$ dextrose, with epinephrine diluted to 1:200,000, was then administered.

To control restlessness during induction, the first 12 infants were sedated with a "brandy soother," containing a small cotton ball soaked in a mixture of equal quantities of brandy and $10 \%$ dextrose. One infant had an apnoeic spell during preparation for lumbar puncture, and required immediate bag/mask ventilation. This preoperative sedation was abandoned after further respiratory problems were experienced.

To achieve adequate spread and duration of analgesia with hyperbaric local anaesthetic agent injected in the sitting position, the dose was progressively increased. Eleven infants received a mean dose of $0.52 \mathrm{mg} \cdot \mathrm{kg}^{-1}$ and 11 received a mean dose of $0.73 \mathrm{mg} \cdot \mathrm{kg}^{-1}$. Seventeen infants received a mean dose of $0.90 \mathrm{mg} \cdot \mathrm{kg}^{-1}$ (Table III). In ten of this group intentionally high spinal anaesthesia

TABLE III Dose of tetracaine

\begin{tabular}{lllll}
\hline & $\begin{array}{l}\text { Lat. decubirus } \\
n=5\end{array}$ & $\begin{array}{l}\text { Sitting } \\
n=11\end{array}$ & $\begin{array}{l}\text { Sitring } \\
n=11\end{array}$ & $\begin{array}{l}\text { Sitting } \\
n=17\end{array}$ \\
\hline Mean dose $\mathrm{mg} \cdot \mathrm{kg}^{-1}$ & 0.29 & 0.52 & 0.73 & 0.90 \\
Duration $\min$ & $105(60,135)^{*}$ & $116(70,145)^{*}$ & $126(85,180)$ & $142(80.210)^{*}$ \\
Spinal anaesth. alone & 3 & 3 & 7 & 11 \\
Sp. anaesth. $+\mathrm{GA}$ & 2 & 1 & 3 & 6 \\
Sp. anaesth. $+i v$ ketamine & & 5 & 1 & \\
Sp. anacsth. $+i v$ ket. $+\mathrm{GA}$ & & 2 & & \\
\hline
\end{tabular}

*Mean (min, max). 
was achieved with the final $0.5 \mathrm{mg}$ injected in the lateral position with a $10^{\circ}$ head-down tilt. After respiratory complications were experienced, this technique was abandoned. The dose of $1 \%$ tetracaine finally adopted was $0.8 \mathrm{mg} \cdot \mathrm{kg}^{-1}$, with $0.7 \mathrm{mg} \cdot \mathrm{kg}^{-1}$ given with the infant sitting. The stylette was replaced, but the needle was left in siru, and the infant was placed in the lateral horizontal position with the operative side down. After confirmation of continued flow of CSF, a further dose of tetracaine was then injected to increase the total to $0.8 \mathrm{mg} \cdot \mathrm{kg}^{-1}$. The needle was not removed until flaccid paralysis of the legs, which appeared within two or three minutes, confirmed successful subarachnoid block. The infant was observed for evidence of untoward reaction. Testing for the level of analgesia in irritable infants was not always possible.

Appearance of blood rather than CSF at the needle hub was the commonest indicator of difficulty. When this occurred, the stylette was replaced and the needle left in situ to act as a marker and also to reduce the leakage of blood from the punctured epidural vein. A second needle was then introduced at a slightly different angle. If this manoeuvre failed to produce CSF, the attempt was repeated at the $\mathrm{L}_{3-4}$ space. If this also failed, or if after injection of local anaesthetic flaccid paralysis did not appear, the attempt was abandoned. Surgery was postponed or alternative regional anaesthetic techniques considered.

Mask inhalational anaesthesia was administered after three failed spinal attempts and after five inadequate spinal blocks following difficult lumbar puncture. Anaesthesia was maintained with $0.5-1.0 \%$ halothane in air $/ \mathrm{O}_{2}$ and the $\mathrm{FlO}_{2}$ was adjusted so that the $\mathrm{SaO}_{2}$ was $>90 \%$ and $<100 \%$. In 15 patients who had had successful spinal anaesthesia, restlessness was controlled with mask inhalational anaesthesia in seven, and with $i v$ ketamine in six $\left(\max 1 \mathrm{mg} \cdot \mathrm{kg}^{-1}\right)$ and two infants received both inhalational anaesthesia and ketamine (Table IV).

Most hernias, 34 of 47, were large and required formal herniorrhaphy. Eleven infants had bilateral hernias (Figure); because of the large size most, 10 of 11 , were repaired as staged procedures. Orchidopexy, which increased the technical difficulty and the operating time,

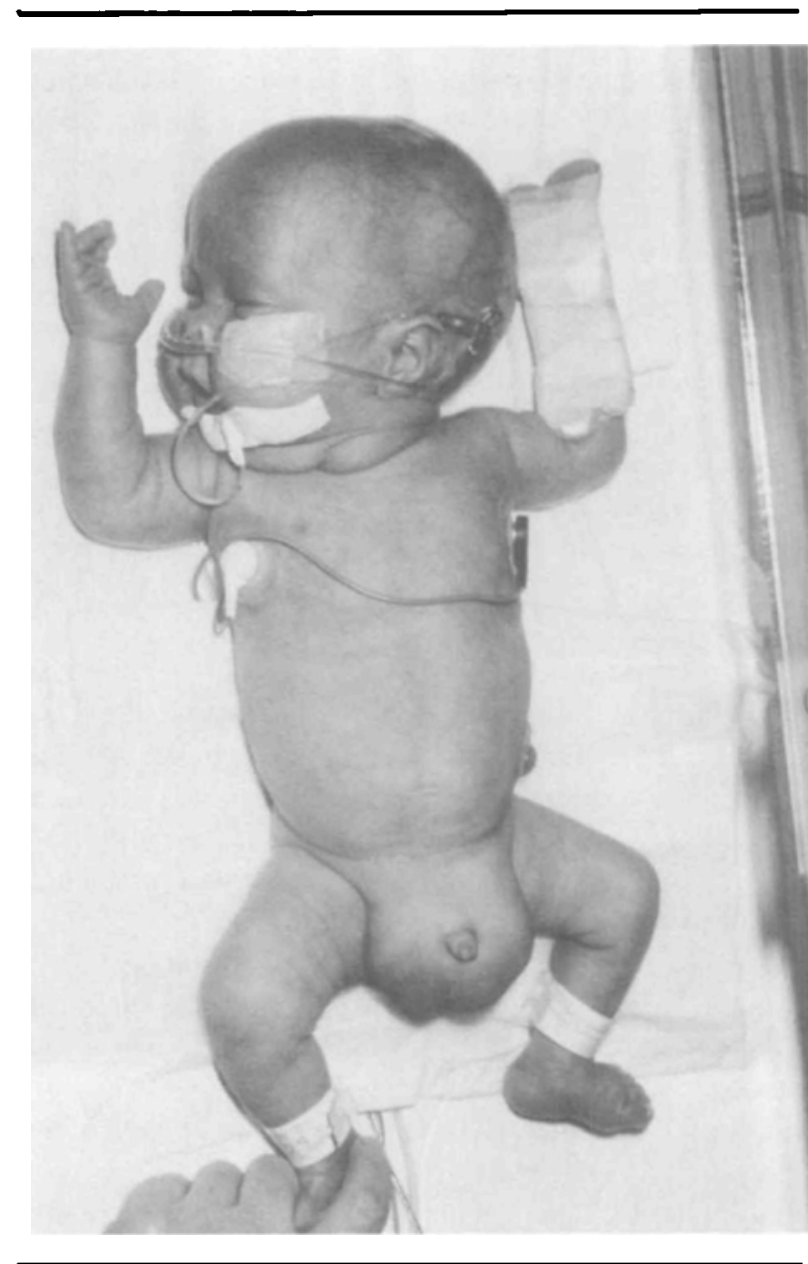

FIGURE

was required in eight infants. In each of the six female infants, a large unilateral sliding hernia of the ovary and fallopian tube was present.

\section{Postoperative care}

Continuous cardiorespiratory monitoring was maintained for $24 \mathrm{hr}$ after surgery. Oral feeding was resumed within four to six hours, and analgesia was provided if necessary with acetaminophen $10-15 \mathrm{mg} \cdot \mathrm{kg}^{-1}$ po.

TABLE IV Results of attempted spinal anaesthesia

\begin{tabular}{lc}
\hline Spinal anaesthesia alone & $24(51 \%)$ \\
Failed lumbar puncture; mask general anaesthesia & $3(6.4 \%)$ \\
Difficult lumbar puncture & $10(21.3 \%)$ \\
- with adequate analgesia requiring mask general anaesthesia & $5(10.6 \%)$ \\
Restlessness during surgery after successful subarachnoid block & $15(32 \%)$ \\
- treated with mask general anaesthesia & $7(14.9 \%)$ \\
- treated with iv ketamine & $6(12.8 \%)$ \\
- treated with iv ketamine + mask GA & $2(4.26 \%)$ \\
\hline
\end{tabular}




\section{Results}

The results of our experience are summarized in Tables III, IV and V. Forty-four spinal anaesthetics were administered for 47 procedures and in $24(51 \%)$, spinal anaesthesia alone provided satisfactory operating conditions. Lumbar puncture was unsuccessful in three infants who received mask inhalational anaesthesia, and was difficult in ten. After five of the ten difficult lumbar punctures, spinal anaesthesia was inadequate and required supplementary mask inhalational anaesthesia. During fifteen procedures following successful subarachnoid block induced without technical difficulty, the infant became restless during surgery and supplementary anaesthesia was required to restore adequate operating conditions.

When spinal anaesthesia was induced with the infant in the sitting position, with increasing dose of local anaesthetic the need for supplementary anaesthesia was reduced, and the mean duration of anaesthesia was extended (Table III). Ten infants with high spinal anaesthesia to $T_{4}-T_{2}$, tested by unresponsiveness to skin pinching, required no supplementary medication. Within each of four mean dose ranges there was wide variation in the duration of the block, measured from the time of induction to return of leg movement. There was no haemodynamic instability, even in those infants with high spinal anaesthesia. Twenty-four infants required no postoperative analgesia.

Perioperative apnoea requiring immediate bag/mask ventilation occurred in six infants: before induction of spinal anaesthesia in one; immediately after induction of high spinal anaesthesia in two; and after iv ketamine in three. Intraoperative periodic breathing with desaturation $\left(\mathrm{SaO}_{2}<80 \%\right)$ occurred during high spinal anaesthesia in four infants, and after iv ketamine in one (Table V). Desaturation was immediately corrected by bag/mask assisted ventilation with increased $\mathrm{FlO}_{2}$. No infant required tracheal intubation.

Ten postoperative apnoeic episodes, defined as respiratory arrest longer than $20 \mathrm{sec}$, were observed in five infants, occurring between 4.5 and $29 \mathrm{hr}$ after surgery. Six of the ten apnoeic spells occurred with feeding. All infants had BPD, one was oxygen-dependent at the time of surgery, and one was receiving a respiratory stimulant. All had received supplemental mask inhalational general anaesthesia and had mild apnoea responsive to stimulation. No infant required bag/mask assisted ventilation, tracheal intubation, or reinstitution of respiratory stimulants.

There were no surgical complications apart from one late recurrence. Two infants died several months after surgery, following reinstitution of ventilator care unrelated to the surgery.
TABLE V Respiratory Complications

\begin{tabular}{ll}
\hline Perioperative & \\
- Apnoca & 1 \\
- Beforc induction of spinal anaesthesia & 2 \\
- Immediately after induction of high sp. anaesth. & 3 \\
- After $i v$ ketamine given for restlessness & \\
Periodic breathing & 4 \\
- During high spinal anaesthesia & 1 \\
- After $i v$ ketamine & \\
Postoperative & 10 \\
- Apnoeic spells (5 infants)
\end{tabular}

\section{Comment}

In these small neonates, technical difficulty was an obstacle to successful spinal anaesthesia. When the infant was held in the sitting position with the head supported and somewhat extended, identification of bony landmarks and anatomical orientation was facilitated. The lower end of the spine was more easily stabilized and flexed by placement of the buttocks on a firm surface. There is evidence that oxygenation is better than in the lateral decubitus position. ${ }^{10}$ Lumbar puncture may be facilitated by the higher hydrostatic pressure in the lumbar cistern.

Having identified the subarachnoid space, delicacy of touch was required to attach the syringe and inject local anaesthetic solution without dislodging the needle. This problem may be minimized by attaching a short iv extension (Abbott Extension Set with "T") " to the hub of the spinal needle, after free flow of CSF has been established. Allowance must be made for the internal volume of the extension set before injecting small volumes of local anaesthetic solution. Microcatheters designed to pass through a $22 \mathrm{G}$ needle are now available. Thus, renewed interest in continuous spinal anaesthesia (CSA) suggests potential advantages for neonatal spinal anaesthesia. ${ }^{12}$

\section{Discussion}

The choice of anaesthesia in this patient population is complicated by unique anatomical and physiological problems. Immature respiratory musculature and central control mechanisms, an unstable elastic rib cage, upper airways that are prone to obstruction and lower airways to collapse, contribute to the risk of apnoeic episodes and hypoventilation during and after general anaesthesia. The risk of apnoea after general anaesthesia persists for up to $48 \mathrm{hr}^{4}{ }^{4}$ In 33 similar infants undergoing inguinal hernia repair with general anaesthesia, ${ }^{3} 79 \%$ required tracheal intubation, and $11(33 \%)$ developed respiratory complications. The most frequent was apnoea which occurred either during surgery or within $12 \mathrm{hr}$ postoperatively. There were two cases of aspiration pneumonia. Although apnoea was recognized early and responded to stimulation 
and ventilation by bag and mask, there is the immediate risk of a life-threatening hypoxic crisis. The possible need for emergency reintubation and mechanical ventilation reintroduces the risks of trauma and infection to an already compromised respiratory system. ${ }^{13,14}$

The technical difficulty of spinal anaesthesia in small infants is compounded by restlessness and irritability, unavoidable responses of the neonate to interruption of feeding, an unfamiliar environment, and the discomfort of lumbar puncture. After difficult lumbar puncture, the quality and duration of spinal anaesthesia were often unreliable, despite initial positive evidence of subarachnoid block.

Restlessness was frequent even in the presence of initial evidence of effective subarachnoid block. It was then uncertain whether it was the result of inadequate analgesia or of irritability. Operating conditions became unsatisfactory as the bowel was forced into the hemial sac by the increased intra-abdominal pressure associated with crying. Satisfactory operating conditions were easily restored and the airway was controlled without undue difficulty with mask anaesthesia using halothane. The need for sedation or supplementary general anaesthesia may be accompanied by the risk of respiratory complications ${ }^{15,16}$ that spinal anaesthesia is intended to avoid.

We observed that previously restless infants frequently became peaceful when spinal anaesthesia took effect. As in adults, the higher the level of spinal anaesthesia, ${ }^{17.18}$ the more pronounced the drowsiness became. Furthermore, if patients with high spinal anaesthesia are given an inhalational anaesthetic, very low concentrations of anaesthetic agents are required to maintain unconsciousness. ${ }^{19}$ On the basis of these observations and the haemodynamic stability previously reported, ${ }^{9.20 .21}$ an attempt was made to control restlessness during surgery by deliberate induction of high spinal anaesthesia. Although this objective was achieved, after experience of transient apnoea and periodic breathing, deliberate induction of high spinal anaesthesia was discontinued. Harnik $^{22}$ reported a case of apneoa and bradycardia following injection of tetracaine, which required tracheal intubation and assisted ventilation. It is postulated that extensive reduction of sensory input in high spinal anaesthesia could adversely affect respiratory control mechanisms in these vulnerable infants.

The factors that determine spread and duration of subarachnoid block: dose and volume of local anaesthetic drug; specific gravity, position and turbulence; are less clearly established and easily controlled than in the adult. It has been suggested that for spinal anaesthesia in small neonates the dose of local anaesthetic agent needed is relatively larger and the duration of anaesthesia is briefer than in larger subjects. ${ }^{8,9,22-24}$ The apparent difference in pharmacokinetic behaviour of subarachnoid anaesthesia between small infants and adults is attributed to the relative differences in the volume of CSF, diameter and surface area of nerve roots and spinal cord, and rates of absorption of local anaesthetic from the subarachnoid space. The volume of CSF in the adult is estimated to be approximately $2.0 \mathrm{ml} \cdot \mathrm{kg}^{-1}$, and in the infant $<15 \mathrm{~kg}, 4.0$ $\mathrm{ml} \cdot \mathrm{kg}^{-1}$ divided equally between the spinal and cranial compartments. ${ }^{25}$ The effect of leakage from the spinal CSF volume of the small infant, through removal of the needle before fixation of local anaesthetic drug or through unrecognized subarachnoid punctures, could be more important than in adults. The effect of the volume of anaesthetic solution injected on the spread of spinal anaesthesia in small infants has yet to be examined. Also, the technique of barbotage is a less practical option in the small infant. Leakage artefact and limited intrathecal distribution of local anaesthetic drug could contribute to the variations of dose, effect and duration that we have observed.

The objectives of anaesthesia for inguinal hernia repair in the high-risk neonate are to provide analgesia and relaxation, minimal physiological disturbance, rapid recovery, and avoidance of the complications inherent in prematurity and secondary to its management. General anaesthesia alone in this patient population usually requires tracheal intubation and is accompanied by a high incidence of life-threatening complications. Our experience supports the opinion that spinal anaesthesia is capable of meeting the criteria described, and for the past five years has been our method of choice. Spinal anaesthesia rather than caudal epidural analgesia was preferred because a flow of CSF before and after injection of local anaesthetic drug confirmed correct needle placement, rapid onset of flaccid paralysis of the legs gave clear evidence of successful subarachnoid block, muscular relaxation was more complete, and the risk of local anaesthetic toxicity was minimized by the smaller amount of local anaesthetic drug administered. The principal disadvantages of spinal anaesthesia in these infants were technical difficulty and restlessness, and a spread and duration of analgesia that were less predictable than in adult spinal anaesthesia. When spinal anaesthesia is not possible, caudal analgesia with mask inhalational anaesthesia is a reasonable alternative. Our experience suggests that effective spinal anaesthesia reduces but does not eliminate the risk of respiratory instability. Continuous cardiorespiratory monitoring is essential throughout anaesthesia and is indicated for at least $24 \mathrm{hr}$ after surgery in those infants for whom supplementary medication is necessary. 


\section{References}

1 Edwards DK, Wayne M, Dyer BS, Northway WH. 12 years experience with bronchopulmonary dysplasia. Pcdiatrics 1977; 59: 839-46.

2 Henderson-Smari DJ, Petrigrew AG, Cambell DJ. Clinical apnea and brain stem neural function in preterm infants. N Engl J Med 1983; 308: 353-7.

3 Steward DJ. Preterm infants are more prone to complications following minor surgery than are term infants. Ancsthesiology 1982; 56: 304-6.

4 Liu LMP, Cote CJ, Goudzouzian NG et al. Life threatening apnea in preterm infants recovering from anesthesia. Anesthesiology 1983; 59: 506-10.

5 Gregory GA, Steward DJ. Life-threatening perioperative apnca in the "ex-premie". Anesthesiology 1983; 59: 495-8.

6 Kurth CD, Spitzer AR, Broennle AM, Downes JJ. Postoperative apnca in preterm infants. Anesthesiology 1987; 66: 483-8.

7 Harper $R G$, Garcia A, Sia C. Inguinal hernia: a common problem of premature infants weighing $1000 \mathrm{~g}$ or less at birth. Pediatrics 1975; 56: 112-5.

8 Abajian JC, Mellish RWP, Browne AF, Perkins FM. Lambert DJH, Mazuzan JE. Spinal anesthesia for surgery in the high risk infant. Anesth Analg 1984; 63: 359-62.

9 Dohi S, Nairo J, Takahashi T. Age-related changes in blood pressure and duration of motor block in spinal anesthesia. Ancsthesiology 1979; 50: 319-23.

10 Gleason CA, Martin RJ, Anderson JV, Carlo WA, Sanniti $K J$, Fanroff $A A$. Optimal position for a spinal tap in preterm infants. Pediatrics 1983; 71: 31-5.

11 Blaise GA, Roy WL. Spinal anaesthesia for minor paediatric surgery. Can Anacsth Soc J 1986; 33: 227-30.

12 Hurley RJ, Lambert $D H$. Continuous spinal anesthesia with a microcatheter technique: preliminary experience. Anesth Analg 1990; 70: 97-102.

13 Joshi W, Mandavia SG, Stern L, Wiglesworth FW. Acute lesions introduced by endotracheal intubation. Am J Dis Child 1972; 124: 646-9.

14 Pusey VA, Macpherson RI, Chernick V. Pulmonary fibroplasia following prolonged artificial ventilation of the newbom infant. Can Med Assoc J 1969; 100: 451-8.

15 Knill RL, Gelb $A W$. Ventilatory responses to hypoxia and hypercapnia during halothane sedation and anesthesia in man. Anesthesiology 1978; 49: 244-51.

16 Gelb AW, Knill RL. Subanacsthetic halothane: its effect on regulation of ventilation and relevance to the recovery room. Can Anacsth Soc J 1978; 25: 488-94.

17 Koster H, Kasman LP. Spinal anesthesia for the head, neck, and thorax; its relation to respiratory paralysis. Surg Gynecol Obstet 1929; 49: 617-30.
18 Huvos MC, Greene NM, Glaser GH. Elcctroencephalographic studies during acute subtotal sensory denervation in man. Yale J Biol Med 1962; 34: 592-7.

19 Greene NM. Physiology of Spinal Ancsthesia. 3rd ed. Baltimore/London: Williams and Wilkins, 1981.

20 Junkin CI. Spinal anacsthesia in children. Can Mcd Assoc J 1933; 26: 5I-3.

21 Melman E, Penuelas J, Marrufo J. Regional anesthesia in children. Anesth Analg 1975; 54: 387-9.

22 Harnik EV, Hoy GR, Potolicchio S, Steart DR, Siegelman $R E$. Spinal ancsthesia in premature infants recovering from respiratory distress syndrome. Anesthesiology 1986; 64: 95-9.

23 Rice L, Demars P. Crooms J, Whalen T. Duration of spinal anesthesia in infants under one year of age: comparison of three drugs. Ancsth Analg 1987; 66: S148.

24 Blaise GA, Roy WL. Spinal anesthesia in children. Anesth Analg 1984; 63: 1140-1.

25 Dalens BJ (Ed.). Pediatric Regional Anesthesia. Boca Raton, Florida: CRC Press, 1990. 